\title{
Stump Appendicitis with Diagnostic Dilemma: A Case Report
}

\author{
Anil Kumar Sah*1, Rajeev Kumar Pandit², Muza Shrestha², \\ Sundar Maharjan², Suman Prasad Sah² \\ 'Department of Urology, Nepal Mediciti Hospital, '2Department of General Surgery, \\ Manmohan Memorial Medical College and Teaching Hospital Kathmandu, Nepal
}

\begin{abstract}
Stump appendicitis is a rare delayed complication of incomplete appendectomy. The clinical symptoms and signs are like acute appendicitis. The possibility of stump appendicitis is not clear to all clinicians. It represents a diagnostic dilemma with incidence of one in 50,000 cases. We report how we encountered diagnostic dilemma during the management of a 30 years old male patient of acute abdomen with history of appendectomy done for acute appendicitis even years back.
\end{abstract}

Keywords: Acute Abdomen, acute appendicitis, appendectomy, clinician's dilemma, stump appendicitis.

\section{*Correspondence:}

Dr. Anil Kumar Sah

FCPS Urology Resident

Department of Urology, Nepal Mediciti

Hospital, Kathmandu

Email: anil.frens@gmail.com

Submitted: July 3, 2021

Accepted: August 10, 2021

To cite: Sah AK, Pandit RK, Shrestha M, Maharjan S, Sah SP. Stump Appendicitis with Diagnostic Dilemma: A Case Report. JGMC Nepal. 2021;14(2):160-2.

DOI:10.3126/jgmcn.v14i2.38083

\section{INTRODUCTION}

Stump appendicitis is infection or inflammation of residual tissue stump of appendix after partially done appendectomy. ${ }^{1}$ As its incidence is very low, clinician may not think of it when a patient presents with similar clinical features of appendicitis in post appendectomy patient. The treatment may be delayed, and patient may land up with complication like perforation, peritonitis, sepsis or abscess formation. ${ }^{2}$ We presented a case of 30 years old male who presented in emergency room after seven years of appendectomy.

\section{CASE REPORT}

A 30 years old male patient presented with complaint of pain in periumbilical region and which was shifting to right lower quadrant for one day. The pain was acute in onset, continuous, severe, with no aggravating or relieving factors and was not associated with fever, loss of appetite, altered bowel habit or urinary symptoms. Patient had undergone open appendectomy seven years back and recovery was uneventful, but the details of operative findings and histopathology report were not available. He had no significant medical history. He was ill looking with gross tenderness in right iliac fossa (RIF) on examination. The leukocyte counts and urine analysis were within normal limit. The ultrasonographic of abdomen and pelvis showed echogenic omentum with free fluid at RIF. Computed Tomography (CT) scan of abdomen and pelvis showed the findings of tubular structure at base of cecum measuring about $18 \mathrm{~mm}$ in length and $7.1 \mathrm{~mm}$ in maximum diameter with extensive peri-appendiceal fat stranding, minimum fluid tracking seen around the cecum (Figure 1 and 2). We could not reach a conclusive diagnosis even at the end of clinical and radiological evaluation. Diagnostic laparoscopy showed dense omental adhesion in RIF, therefore the procedure 
was converted to open with a grid iron incision at RIF. The adhered omentum was separated and residual stump of appendix about $2 \mathrm{~cm}$ was noted with inflammation. A final conclusive diagnosis of inflamed appendicular stump was made (Figure 2). Stump appendectomy was done. Rest of bowel was normal. Postoperative period remained uneventful. The patient was discharged on third post-operative day. The histopathological report showed acutely inflamed appendix. He progressed well during recent six month of the follow up.
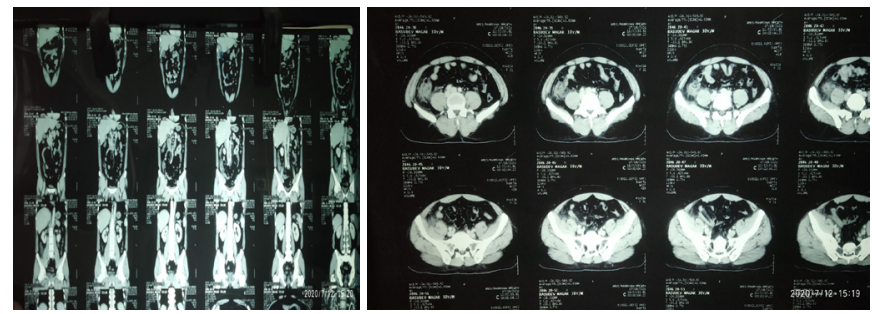

Figure 1a, 1b: CECT Abdomen and pelvis saggital view $\mathrm{B}$-axial view, shows appedix measuring $18 \mathrm{~mm}$ with periappendiceal collection

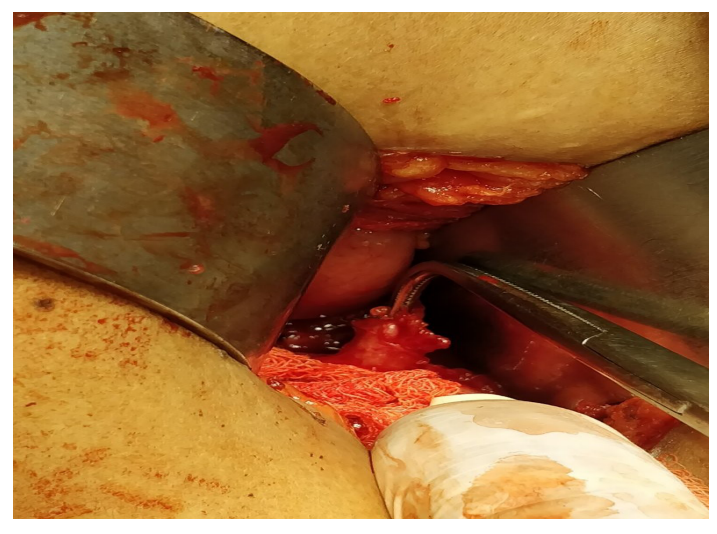

Figure 2: Intraoperative image showing inflamed appendicular stump

\section{DISCUSSION}

Appendicitis is most common disease encountered to surgeons and appendectomy is most common operative done worldwide (38.9\%). The first case of stump appendicitis in a post appendectomy patient was described by Rose in $1945 .^{4}$

The postoperative complications after appendectomy include wound infection, pelvic abscess, portal pyemia, hemorrhage, intestinal, peritonitis, adhesion,perforation. ${ }^{5,6}$ Our case did not reveal any of the commonly seen complications. He developed the features suggestive of stump appendicitis, which is rare and delayed complication of appendectomy. The lifelong probability of developing acute appendicitis is estimated at seven percent, but the probability of developing stump appendicitis is much lower $(1 / 50,000) .{ }^{2}$ Early diagnosis and treatment are essential to prevent the complication.

Stump appendicitis may lead to diagnostic dilemma to unfamiliar physician with this rare entity like we faced during the management. ${ }^{7}$ Stump appendicitis clinically presents with similar symptoms and signs as acute appendicitis in a previously appendectomy patient in most of the cases, but some of the cases may be difficult to conclude even after thorough clinical and radiological work ups like in our case. Clinical, radiological and diagnostic laparoscopy was inconclusive in this case.

The answer to "why is the preliminary diagnosis of stump appendicitis difficult at first referral" is the previous appendectomy history. Consequently, diagnosis is delayed which further results delayed proper treatment and subsequent morbidity. A large retrospective study of 3130 patients of stump appendicitis by Dikicier et al. ${ }^{1}$ suggested that awareness of this condition before radiological investigations may facilitate accurate diagnosis and decrease the duration of the decision-making process, leading to decreased morbidity.

Generally, stump appendicitis can be prevented by adequate visualization of appendix baseand ileocecal junction and leaving stump $<5 \mathrm{~mm}$ long. ${ }^{8,9}$ The common condition that leads to stump appendicitis are inadequate visualization of appendicular-cecal base, subserosal appendix, retrocecal appendix, extensive local inflammation, local ulceration due to fecolith, difficult dissection. Since his appendectomy had been performed at another center, the retrieval of previous operative details could not be possible. This was one of the limitations in the management of this case. Difficulty while doing previous appendectomy and the length of residual stump could not be assessed.

Pre- operative diagnosis with USG is difficult like in our case. It needs a high level of suspicion and expertise, but USG can rule out other abdominal causes. CT scan of abdomen is more specific for diagnosis of stump appendicitis. ${ }^{1,2,8,10}$ The CT scan findings are like acute appendicitis, like in our case. Laparoscopy is next method to make diagnosis in case of confusion with radiological diagnosis.Completion appendectomy (open or laparoscopy) is necessary to treat stump appendicitis. ${ }^{3,8}$

\section{CONCLUSIONS}

Stump appendicitis is a diagnostic dilemma. It may be confused with other acute abdominal condition. Stump appendectomy is advised once the confirmatory diagnosis 
is made.

CONFLICT OF INTEREST: None declared

CONSENT FROM PATIENT: The patient has provided consent for publication of the case.

\section{REFERENCES}

1. Dikicier E, Altintoprak F, Ozdemir K, Gundogdu K, Uzunoglu MY, Cakmak G, et al. Stump appendicitis: A retrospective review of 3130 consecutive appendectomy cases. World J Emerg Surg. 2018;13:14. DOI:10.1186/s13017-018-0182-5 PMID: 29849750.

2. Liang MK, Lo HG, Marks JL. Stump appendicitis: A comprehensive review of literature. Am Surg. 2006;72(2):162-6. DOI:10.1177/000313480607200214 PMID: 16536249 .

3. Di Saverio S, Podda M, De Simone B, Ceresoli M, Augustin G, Gori A, et al. Diagnosis and treatment of acute appendicitis: 2020 update of the WSES Jerusalem guidelines. World J Emerg Surg. 2020;15(1):27. DOI:10.1186/s13017-020-00306-3 PMID: 32295644.

4. Rose TF. Recurrent appendiceal abscess. Med J Aust. 1945;1:659-62. DOI:10.5694/j.1326-5377.1945. tb55065.x

5. Madden JL. Immediate complications following appendectomy. Surg Clin North Am. 1964;44:411-29. DOI:10.1016/S0039-6109(16)37239-5.

6. Rasmussen T, Fonnes S, Rosenberg J. Long-Term Complications of Appendectomy: A Systematic Review. Scand J Surg. 2018 Sep;107(3):189-96.. DOI:10.1177/1457496918772379 PMID: 29764306.

7. Roberts KE, Starker LF, Duffy AJ, Bell RL, Bokhari J. Stump appendicitis: A surgeon's dilemma. JSLS. 2011;15(3):373-8. DOI:10.4293/10868081 1X13125733356954 PMID: 21985727.

8. Humes DJ, Simpson J. Acute appendicitis. BMJ. 2006;333(7567):530-4.. DOI:10.1136/ bmj.38940.664363 PMID: 16960208.

9. Subramanian A, Liang MK. A 60-year literature review of stump appendicitis: the need for a critical view. Am J Surg. 2012;203:503-7. DOI:10.1016/j. amjsurg.2011.04.009 PMID: 22153086.

10. Al-Dabbagh AK, Thomas NB, Haboubi N. Stump appendicitis. A diagnostic dilemma. Tech Coloproctol. 2009;13:73-4. DOI:10.1007/s10151-008-0419-5 PMID: 18545872. 